Journal of Computer Science 5 (12): 915-921, 2009

ISSN 1549-3636

(C) 2009 Science Publications

\title{
Formalized Model of Stabile Reengineering Information System Functional Elements (Business Processes)
}

\author{
Zahi A. Abu Sarhan \\ Department of Computerized Information Systems, \\ Applied Science Privet University Amman, Shafa-Badran 11931, Amman, Jordan
}

\begin{abstract}
The process of reengineering the functional elements of management information system must presented as stable, in which all the kernel functional components of the management information system should be saved. Problem statements: There is no formalized models for stabile reengineering for the functional structure (functional elements) for various information systems types, therefore the process of reengineering is not stabile and may be it finished with failure reengineering process or failure information system. Approach: The information system development Approach and the mathematical methods to formalized the detailed mathematical model for the information systems stabile reengineering, and at different stages of IS reengineering. Results: All process of stabile reengineering at the various stages of it was formalized in mathematical models. Conclusion: The developed models helps the system analyst to define if the reengineering process for the functional structure of information system will be stabile and effective or not, and if it more feasible than creating new information system.
\end{abstract}

Key words: Information systems, business processes, stabile reengineering

\section{INTRODUCTION}

Now majority of existing Information Systems (IS) are represented by complicated systems, which with the current of time developed, improved, or upgraded in the correspondence with changed requests of the enterprisecustomer. In this case the perfecting IS usually happens within the framework of the existing standards, techniques and methods of operation of business, to which concern: Standards MRP (Management Resource Planning) and MRPII, Concept CRP (Client Resource Planning), Supply Chain Management (SCM), Concept ERP (Enterprise Resource Planning) and Enterprise Resource and Relationship Processing/Enterprise Commerce Management (ERPII/ECM) ${ }^{[1]}$.

Reengineering should be an important goal of any effort to develop an Management Information Systems (MIS) plan for an organization symptoms of obsolete design concepts are manifested throughout almost any large application developed a decade or more ago in its failure to satisfy cross functional needs, its limited functional capabilities, its inability to provide selected and tailored information drawn from widespread parts of the organization, its flexibility in meeting changing needs, and its unfriendly interfaces. Traditionally the argument has always been made that the IS planning should closely follow the organizational strategic planning process. The intention is to eventually align the two plans such that execution of strategic plans can be closely supported by organizational information systems. The rationale is that all levels of decision making require ready access to information and if the two plans are well-aligned it would result in development of systems that are highly effective in making decisions ${ }^{[2,3]}$.

However, experience has shown that most organizational systems are developed with no attention to the needs for cross-functional business processes that play an important role in the proper functioning of the organization. These business processes are defined as a collection of activities that takes one or more kinds of input and creates an output that is of value to the customer. Alternatively, business processes can also be defined as, "a set of logically related tasks performed to achieve a defined business outcome." Processes can be understood as "beginning and end points, interfaces, and organization units involved, particularly the customer unit." for Examples of such processes include processing an insurance claim, sales and delivery, management of supply chains, and so on. These business processes become the focal point of every reengineering effort and entail the need to go beyond traditional tasks and functions ${ }^{[4,5]}$.

However, despite more and more innovative technological solutions for business processes, resistance to change continues to be the biggest BPR 
obstacle. According to many experts, this is the main reason why reengineering projects in many organizations fail ${ }^{[6-8]}$.

Problem statement: However all listed above standards, techniques and methods are oriented, first, to develop new IS or new subsystems. At the same time, the main problem of creation IS consists mainly of modernizing, development and integration of existing information systems of various subordination in uniform IS of the enterprise or association of the enterprises. In this case the processes of integration limited by the purposes, generally delivered before the enterprise; by necessity of simultaneous mutual coexistence and operation of separate solutions within the framework of uniform IS, by availability of the certain amount of resources (safe life), which ensure operation and development IS.

\section{MATERIALS AND METHODS}

The development of Information Systems (IS), information system reengineering and the mathematical models of IS at various stages of reengineering ${ }^{[9-12]}$. May be proposes to classify all the operations performed at different stages of IS reengineering into two classes:

- Extensive ones, directed on increase of the number of various elements added to IS (new functional tasks and modules, software and technical complexes, database tables, queries to databases

- Intensive ones that allow improving the IS structures according to the changes in external and internal condition of functioning

Operations of the both classes should be performed in compliance to the following requirements:

- IS correspondence to new requirements and criteria determined during the reengineering

- Stability of 'the kernel' (main elements) of IS to changes that occur during IS reengineering

Thus IS reengineering regardless of class of the operations should be considered as solution of the problem of determination of IS state of the totally of states which are the most stabile under the given conditions of exploitation as well as correspond to the given efficiency criteria and requirements to $\mathrm{IS}^{[13-17]}$.

General model information systems: Purpose we used the complex IS mathematical models based on the mathematical apparatus of the general theory of systems. According to this theory IS should be described with the aid of the following model ${ }^{[9]}$ :

$$
\mathrm{S}=<\{\mathrm{M}\} \mathrm{T}\{\mathrm{R}\} \mathrm{T}\{\mathrm{Z}\}>,\{\mathrm{M}\} \subseteq \mathrm{U},\{\mathrm{A}\} \subseteq \mathrm{U}
$$

Here:

$\mathrm{S} \quad=\mathrm{A}$ model of IS structures totality given by composition (1)

$\{\mathrm{M}\}=$ Set of 'primary elements' (elements that should be determined before definition of IS structure S)

$\{\mathrm{R}\}=$ Set of relations, determinate on elements of set $\{\mathrm{M}\}$

$\{Z\}=$ Set of conditions limiting relations $\{R\}$ on set $\{\mathrm{M}\}$

$\mathrm{U}=$ Universe from which the primary elements $\mathrm{m}$ of set $\{\mathrm{M}\}$ are selected

$\{\mathrm{A}\}=$ Set of substitutions that determine the rules of selection of 'primary elements' $m$ of set $\{\mathrm{M}\}$

$\mathrm{T}=$ Totality of composition laws that determine the rules of synthesis out of sets $\{M\},\{R\}$ and $\{Z\}$ are IS of $\mathrm{S}$

General model of reengineering information system: Then the conditions of IS during reengineering can be described as follows: Suppose that during IS exploitation some defects caused by lapses in functioning of business-processes were found. To eliminate these defects we need to change the IS functional structure $\mathrm{L}_{\mathrm{Fu}}$ its model in a general case coincides with the model (1) and looks as follows:

$$
\begin{aligned}
\mathrm{S}_{\mathrm{L}_{\mathrm{Fu}}}= & <\left\{\mathrm{M}_{\mathrm{L}_{\mathrm{Fu}}}\right\} \mathrm{T}\left\{\mathrm{R}_{\mathrm{L}_{\mathrm{Fu}}}\right\} \mathrm{T}\left\{\mathrm{Z}_{\mathrm{L}_{\mathrm{Fu}}}\right\}>,\left\{\mathrm{M}_{\mathrm{L}_{\mathrm{Fu}}}\right\} \subseteq \mathrm{U}_{\mathrm{L}_{\mathrm{Fu}}}, \\
& \left\{\mathrm{A}_{\mathrm{L}_{\mathrm{Fu}}}\right\} \subseteq \mathrm{U}_{\mathrm{L}_{\mathrm{Fu}}}
\end{aligned}
$$

Here:

$\mathrm{S}_{\mathrm{L}_{\mathrm{Fu}}}=\mathrm{A}$ model of functional structure $\mathrm{L}_{\mathrm{Fu}}$ of the analyzed IS

$\left\{\mathrm{M}_{\mathrm{L}_{\mathrm{Fu}}}\right\}=$ Set of functions or operations that constitute the functional structure, the automation of them allows ensure meeting of the client's requirements.

$\left\{R_{L_{\mathrm{Fu}}}\right\}=$ Set of relations determinate on the elements of set $\left\{\mathrm{M}_{\mathrm{L}_{\mathrm{Fu}}}\right\}$, i.e., set of information stream among functions or operations of IS to be automated

$\left\{\mathrm{Z}_{\mathrm{L}_{\mathrm{Fu}}}\right\}=$ Set of conditions that limit relations of $\operatorname{set}\left\{\mathrm{R}_{\mathrm{L}_{\mathrm{Fu}}}\right\}$, i.e., set of limitations on 
information streams complying with the particular features of IS implementation and the client's requirements

$\mathrm{U}_{\mathrm{L}_{\mathrm{Fu}}}=$ Universe of controlling functions (operations), determined by the actual methods of an enterprise's management

$\left\{\mathrm{A}_{\mathrm{L}_{\mathrm{Fu}}}\right\}=$ Set of the client's requirements determining the rules of selection of automated functions (operations) $\left\{\mathrm{M}_{\mathrm{L}_{\mathrm{Fu}}}\right\}$ universe $\mathrm{U}_{\mathrm{L}_{\mathrm{Fu}}}$

Whatever modifications should be made in the supporting structure of IS, the model of functional structure $\mathrm{L}_{\mathrm{Fu}}$ after the reengineering processes will be as follows:

$$
\begin{aligned}
S_{\mathrm{L}_{\mathrm{Fu}}}^{\prime}= & <\left\{\mathrm{M}_{\mathrm{L}_{\mathrm{Fu}}}^{\prime}\right\} \mathrm{T}\left\{\mathrm{R}_{\mathrm{L}_{\mathrm{Fu}}}^{\prime}\right\} \mathrm{T}\left\{\mathrm{Z}_{\mathrm{L}_{\mathrm{Fu}}}^{\prime}\right\}>, \\
& \left\{\mathrm{M}_{\mathrm{L}_{\mathrm{Fu}}}^{\prime}\right\} \subseteq \mathrm{U}_{\mathrm{L}_{\mathrm{Fu}}},\left\{\mathrm{A}_{\mathrm{L}_{\mathrm{Fu}}}^{\prime}\right\} \subseteq \mathrm{U}_{\mathrm{L}_{\mathrm{Fu}}}
\end{aligned}
$$

Here:

$\mathrm{S}_{\mathrm{L}_{\mathrm{Fu}}}^{\prime} \quad=\mathrm{A}$ model of IS, functional structure $\mathrm{L}_{\mathrm{Fu}}$ after reengineering

$\left\{\mathrm{M}_{\mathrm{L}_{\mathrm{Fu}}}^{\prime}\right\}=$ Set of 'primary elements' of functional structure $\mathrm{L}_{\mathrm{Fu}}$ after reengineering

$\left\{\mathrm{R}_{\mathrm{L}_{\mathrm{fu}}}^{\prime}\right\}=$ Set of relations (information streams among functions) determinate on the elements of set $\left\{\mathrm{M}_{\mathrm{L}_{\mathrm{Fu}}}^{\prime}\right\}$ after reengineering

$\left\{\mathrm{Z}_{\mathrm{L}_{\mathrm{Fu}}}^{\prime}\right\}=$ Set of conditions that limit relations of set $\left\{\mathrm{R}_{\mathrm{L}_{\mathrm{Fu}}}^{\prime}\right\}$ after reengineering

$\left\{\mathrm{A}_{\mathrm{L}_{\mathrm{u}}}^{\prime}\right\}=$ Set of substitutions that determine the rules of selection of set of 'primary elements' $\left\{\mathrm{M}_{\mathrm{L}_{\mathrm{Fu}}}^{\prime}\right\}$ out of universe $\mathrm{U}_{\mathrm{L}_{\mathrm{Fu}}}$ after reengineering

For other types of IS support $\mathrm{L}_{2}, \ldots, \mathrm{L}_{\mathrm{z}}$., (here $\mathrm{z}$ is a number of IS support types) we formalized the descriptions of their structures $\mathrm{S}_{\mathrm{L}_{2}}, \ldots, \mathrm{S}_{\mathrm{L}_{z}}$; similar to expression (2). Thus the processes of reengineering can be presented as formations on the basis of models of existing structures of support types of the totality of models' variants $\mathrm{S}_{\mathrm{L}_{2}}^{\prime}, \ldots, \mathrm{S}_{\mathrm{L}_{z}}^{\prime}$ :

$$
\left\{\begin{array}{l}
\mathrm{S}_{\mathrm{L}_{2}} \rightarrow \mathrm{S}_{\mathrm{L}_{2}}^{\prime} \\
\cdots \\
\mathrm{S}_{\mathrm{L}_{z}} \rightarrow \mathrm{S}_{\mathrm{L}_{z_{z}}}^{\prime}
\end{array}\right.
$$

That takes into consideration the proposed solutions concerning the functional structure $\mathrm{L}_{\mathrm{Fu}}$ :

$$
\begin{aligned}
& S_{L_{i}}=<\left\{M_{L_{i}}\right\} T\left\{R_{L_{i}}\right\} T\left\{Z_{L_{i}}\right\}>,\left\{M_{L_{i}}\right\} \subseteq U_{L_{i}}, \\
&\left\{A_{L_{i}}\right\} \subseteq U_{L_{i}} \rightarrow S_{L_{i}}^{\prime}=<\left\{M_{L_{i}}\right\} T\left\{R_{L_{i}}^{\prime}\right\} T\left\{Z_{L_{i}}^{\prime}\right\}>, \\
&\left\{M_{L_{i}}^{\prime}\right\} \subseteq U_{L_{i}}, \quad\left\{A_{L_{i}}^{\prime}\right\} \subseteq U_{L_{i}} ; i=2, \ldots, Z \\
&\left\{Z_{L_{i}}^{\prime}\right\}=\left\{Z_{L_{i}}\right\} \cup f\left\{Z_{L_{F_{u}}^{\prime}}^{\prime}\right\} ; i=2, \ldots, z \\
&\left\{A_{L_{i}}^{\prime}\right\}=\left\{A_{L_{i}}\right\} \cup f\left\{A_{L_{F_{u}}^{\prime}}^{\prime}\right\} ; i=2, \ldots, Z
\end{aligned}
$$

Here:

$\mathrm{f}\left\{\mathrm{Z}_{\mathrm{L}_{\mathrm{Fu}}}^{\prime}\right\}=\mathrm{A}$ description of operations of transformation of conditions out of set $\left\{\mathrm{Z}_{\mathrm{L}_{\mathrm{Fu}}}^{\prime}\right\}$ determined during reengineering of a functional structure $\mathrm{L}_{\mathrm{Fu}}$

$\mathrm{f}\left\{\mathrm{A}_{\mathrm{L}_{\mathrm{Fu}}}^{\prime}\right\}=$ Description of operations of transformations of substitutions out of set $\left\{\mathrm{A}_{\mathrm{L}_{\mathrm{Fu}}^{\prime}}^{\prime}\right\}$ determined during reengineering of a functional structure $\mathrm{L}_{\mathrm{Fu}}$

The proposed descriptions determine IS reengineering as representation of optimal (or rational) conditions and substitutions of selection of elements of functional structure $\mathrm{L}_{\mathrm{Fu}}$ as consistent with efficiency criteria set beforehand into conditions and substitutions of other types of support. Such an approach allows satisfying the first requirement to IS reengineering.

The inverse transition from models of support type's structures $S_{\mathrm{L}_{2}}^{\prime}, \ldots, \mathrm{S}_{\mathrm{L}_{2}}^{\prime}$ to the model of functional structure $\mathrm{S}_{\mathrm{L}_{\mathrm{Fu}}}^{\prime \prime}$, determining the effect of the obtained solutions from the reengineering of other types of support on IS functional structure can be described as follows:

$$
\begin{aligned}
& \mathrm{S}_{\mathrm{L}_{\mathrm{Fu}}}^{\prime \prime}=<\left\{\mathrm{M}_{\mathrm{L}_{\mathrm{Fu}}}^{\prime \prime}\right\} \mathrm{T}\left\{\mathrm{R}_{\mathrm{L}_{\mathrm{Fu}}}^{\prime \prime}\right\} \mathrm{T}\left\{\mathrm{Z}_{\mathrm{L}_{\mathrm{Fu}}}^{\prime \prime}\right\}>, \\
&\left\{\mathrm{M}_{\mathrm{L}_{\mathrm{Fu}}}^{\prime \prime}\right\} \subseteq \mathrm{U}_{\mathrm{L}_{\mathrm{Fu}}},\left\{\mathrm{A}_{\mathrm{L}_{\mathrm{Fu}}}^{\prime \prime}\right\} \subseteq \mathrm{U}_{\mathrm{L}_{\mathrm{Fu}}} \\
&\left\{\mathrm{Z}_{\mathrm{L}_{\mathrm{Fu}}}^{\prime \prime}\right\}=\left\{\mathrm{Z}_{\mathrm{L}_{\mathrm{Fu}}}^{\prime}\right\} \cup\left[\mathrm{f}\left\{\mathrm{Z}_{\mathrm{L}_{2}}^{\prime}\right\} \cup \ldots \cup \mathrm{f}\left\{\mathrm{Z}_{\mathrm{L}_{\mathrm{i}}}^{\prime}\right\} \cup \ldots \cup f\left\{\mathrm{Z}_{\mathrm{L}_{z}}^{\prime}\right\}\right] \\
&\left\{\mathrm{A}_{\mathrm{L}_{\mathrm{Fu}}}^{\prime \prime}\right\}=\left\{\mathrm{A}_{\mathrm{L}_{\mathrm{Fu}}}^{\prime}\right\} \cup\left[\mathrm{f}\left\{\mathrm{A}_{\mathrm{L}_{2}}^{\prime}\right\} \cup \ldots \cup \mathrm{f}\left\{\mathrm{A}_{\mathrm{L}_{\mathrm{i}}}^{\prime}\right\} \cup \ldots \cup f\left\{\mathrm{~A}_{\mathrm{L}_{z}}^{\prime}\right\}\right]
\end{aligned}
$$

It can hardly seriously affect the developed above model $\mathrm{S}_{\mathrm{Fu}}^{\prime}$ that can be described using conditions:

$$
\left\{\mathrm{M}_{\mathrm{L}_{\mathrm{Fu}}}^{\prime \prime}\right\} \mathrm{T}\left\{\mathrm{R}_{\mathrm{L}_{\mathrm{Fu}}}^{\prime \prime}\right\} \rightarrow\left\{\mathrm{M}_{\mathrm{L}_{\mathrm{Fu}}}^{\prime}\right\} \mathrm{T}\left\{\mathrm{R}_{\mathrm{L}_{\mathrm{Fu}}}^{\prime}\right\}
$$

$\left[f\left\{Z_{L_{2}}^{\prime}\right\} \cup \ldots \cup f\left\{Z_{L_{i}}^{\prime}\right\} \cup \ldots \cup f\left\{Z_{L_{2}}^{\prime}\right\}\right] \rightarrow\{\varnothing\}$ 
$\left[f\left\{A_{L_{2}}^{\prime}\right\} \cup \ldots \cup f\left\{A_{L_{i}}^{\prime}\right\} \cup \ldots \cup f\left\{A_{L_{z}}^{\prime}\right\}\right] \rightarrow\{\varnothing\}$

Fulfillment of conditions (11-13) determines the structural stability of IS to changes and thus ensures meeting the second requirement to IS reengineering.

Stabile IS reengineering can be presented as follows. IS structure (functional or structure of support type) passes into a new stabile state, if the number of changes in IS during reengineering is minimal. In this case the sum of values of efficiency criteria for IS functioning before the reengineering must be less or equal to the sum of values of efficiency criteria for IS functioning after the reengineering.

Suppose $\mathrm{f}=\left(\mathrm{f}_{1}, \mathrm{f}_{2}, \ldots, \mathrm{f}_{\mathrm{n}}\right), \mathrm{n}=\overline{1, \mathrm{n}}$ is the vector of design requirements to IS and $\mathrm{f}^{\prime \prime}=\left(\mathrm{f}_{1}^{\prime \prime}, \mathrm{f}_{2}^{\prime \prime}, \ldots, \mathrm{f}_{\mathrm{n}}^{\prime \prime}\right), \mathrm{n}=\overline{1, \mathrm{n}}$; vector of new requirements to the same IS; $f \in F, f^{\prime \prime} \in F$. Suppose $f_{1}$ is a number of problems that can be solved in the IS, $f_{2}$-amount of the transacted information; $f_{3^{-}}$ time of transaction, $\mathrm{f}_{4}$-of queries to databases, $\mathrm{f}_{5}$-right of access to the data. Suppose for the selected $\mathrm{f}_{\mathrm{i}}$ :

$$
\begin{aligned}
& \mathrm{f}_{\mathrm{i}}=\Psi_{\mathrm{i}}\left(\left\{\mathrm{M}_{\mathrm{L}_{\mathrm{i}}}\right\} \mathrm{T}\left\{\mathrm{R}_{\mathrm{L}_{\mathrm{i}}}\right\} \mathrm{T}\left\{\mathrm{Z}_{\mathrm{L}_{\mathrm{i}}}\right\} \mathrm{T}\left\{\mathrm{A}_{\mathrm{L}_{\mathrm{i}}}\right\}\right), \mathrm{i}=\overline{1, \mathrm{n}} \\
& \mathrm{f}^{\prime \prime}{ }_{\mathrm{i}}=\Psi_{\mathrm{i}}\left(\left\{\mathrm{M}_{\mathrm{L}_{\mathrm{i}}}^{\prime \prime}\right\} \mathrm{T}\left\{\mathrm{R}_{\mathrm{L}_{\mathrm{i}}}^{\prime \prime}\right\} \mathrm{T}\left\{\mathrm{Z}_{\mathrm{L}_{\mathrm{i}}}^{\prime \prime}\right\} \mathrm{T}\left\{\mathrm{A}_{\mathrm{L}_{\mathrm{i}}}^{\prime \prime}\right\}\right), \mathrm{i}=\overline{1, \mathrm{n}}
\end{aligned}
$$

Here $\Psi_{i}(\bullet)$ is a function determining the power of set (number of its elements). Then:

$$
\Delta F=\left|\sum_{i-1}^{n} f_{i}^{\prime \prime}-f_{i}\right|, \quad i=1,2, \ldots, n
$$

here $\Delta \mathrm{F}$ is difference between vectors of requirements to the system.

If $\Delta \mathrm{F}=0$ then there is no necessity in reengineering, otherwise $\Delta \mathrm{F} \neq 0$-the system must be reengineered.

The process of IS reengineering, which is a transition of IS from the actual state (the state of IS during its industrial use) to other, desired state (a state determined by new requirements of users, new features of business-processes, can be described as follows:

$$
\mathrm{S}(\mathrm{x})=\sum_{\mathrm{i}=1}^{\mathrm{n}} \mathrm{V}_{\mathrm{L}_{\mathrm{i}}} \Theta_{\mathrm{L}_{\mathrm{i}}} \rightarrow \mathrm{S}^{\prime \prime}(\mathrm{x})=\sum_{\mathrm{i}=1}^{\mathrm{k}} \mathrm{V}_{\mathrm{L}_{\mathrm{i}}}^{\prime \prime} \mathrm{P}_{\mathrm{L}_{\mathrm{i}}}
$$

Here:

$\mathrm{S}(\mathrm{x})=$ A state of IS before reengineering $\mathrm{S}^{\prime \prime}(\mathrm{x})=$ State of IS after stabile reengineering
$\mathrm{V}_{\mathrm{L}_{\mathrm{i}}}=$ State of $\mathrm{L}_{\mathrm{i}}$-th type of support before reengineering; $\mathrm{V}_{\mathrm{L}_{\mathrm{i}}}^{\prime \prime}$

$=$ state of $\mathrm{L}_{\mathrm{i}}$-th type of support after stabile reengineering

$\Theta_{\mathrm{L}_{\mathrm{i}}}=$ Operator of presence of $\mathrm{L}_{\mathrm{i}}$-th type of support in IS before reengineering (0-if support type $L_{i}$ is absent, 1-if support type $\mathrm{L}_{\mathrm{i}}$ is present)

$\mathrm{n} \quad=$ Number of support types in IS before stabile reengineering

$\mathrm{P}_{\mathrm{L}_{\mathrm{i}}} \quad=$ Operator of presence of $\mathrm{L}_{\mathrm{i}}$-th type of support in IS after stabile reengineering (0-if support type $\mathrm{L}_{\mathrm{i}}$ is absent, 1-if support type $\mathrm{L}_{\mathrm{i}}$ is present)

$\mathrm{k}=$ Number of support types in IS after stabile reengineering

Let's describe functional structure and structures of IS support types as a composition of sets:

$$
\begin{aligned}
S_{L_{i}}(x)= & \left\{M_{L_{i}}\right\} T\left\{R_{L_{i}}\right\} T\left\{Z_{L_{i}}\right\} T\left\{A_{L_{i}}\right\}, \\
& \left\{M_{L_{i}}\right\} \subseteq U,\left\{A_{L_{i}}\right\} \subseteq U \\
S_{L_{i}}^{\prime \prime}(x)= & \left\{M_{L_{i}}^{\prime \prime}\right\} T\left\{R_{L_{i}}^{\prime \prime}\right\} T\left\{Z_{L_{i}}^{\prime \prime}\right\} T\left\{A_{L_{i}}^{\prime \prime}\right\} \\
& \left\{M_{L_{i}}^{\prime \prime}\right\} \subseteq U,\left\{A_{L_{i}}^{\prime \prime}\right\} \subseteq U
\end{aligned}
$$

Then taking into account the modifications made during reengineering the structure of IS can be described as follows:

$$
\mathrm{S}^{\prime \prime}(\mathrm{x})=\sum_{\mathrm{i}=1}^{\mathrm{n}} \mathrm{V}_{\mathrm{L}_{\mathrm{i}}} \Theta_{\mathrm{L}_{\mathrm{i}}}+\sum_{\mathrm{j}=1}^{\mathrm{R}} \mathrm{W}_{\mathrm{j \textrm {L } _ { \mathrm { i } }}}\left|\mathrm{H}_{\mathrm{jL}_{\mathrm{i}}}\right|
$$

Here:

$\mathrm{W}_{\mathrm{j} \mathrm{L}_{\mathrm{i}}}=$ The operator of presence of the. $\mathrm{j}$-th modification that happened during reengineering as support type $\mathrm{L}_{\mathrm{i}}$

$\mathrm{H}_{\mathrm{jL}_{\mathrm{i}}}=$ Modification that during stabile reengineering took form of support type $\mathrm{L}_{\mathrm{i}}$

$\mathrm{R}=$ Number of modifications that during stabile reengineering took form of support type $\mathrm{L}_{\mathrm{i}}$ :

$$
\begin{aligned}
r\left(\mathrm{H}_{\mathrm{L}_{\mathrm{i}}}\right)= & \sum_{\mathrm{i}=1}^{\mathrm{n}}\left(\mathrm{r}\left(\left\{\mathrm{M}^{\prime \prime}{ }_{\mathrm{L}_{\mathrm{i}}}\right\}\right)-\mathrm{r}\left(\left\{\mathrm{M}_{\mathrm{L}_{\mathrm{i}}}\right\}\right)\right) \\
& +\sum_{\mathrm{i}=1}^{\mathrm{n}}\left(\mathrm{r}\left(\left\{\mathrm{R}^{\prime \prime}{ }_{\mathrm{L}_{\mathrm{i}}}\right\}\right)-\mathrm{r}\left(\left\{\mathrm{R}_{\mathrm{L}_{\mathrm{i}}}\right\}\right)\right) \\
& +\sum_{\mathrm{i}=1}^{\mathrm{n}}\left(\mathrm{r}\left(\left\{\mathrm{Z}^{\prime \prime}{ }_{\mathrm{L}_{\mathrm{i}}}\right\}\right)-\mathrm{r}\left(\left\{\mathrm{Z}_{\mathrm{L}_{\mathrm{i}}}\right\}\right)\right) \\
& +\sum_{\mathrm{i}=1}^{\mathrm{n}}\left(\mathrm{r}\left(\left\{\mathrm{A}^{\prime \prime}{ }_{\mathrm{L}_{\mathrm{i}}}\right\}\right)-\mathrm{r}\left(\left\{\mathrm{A}_{\mathrm{L}_{\mathrm{i}}}\right\}\right)\right)
\end{aligned}
$$


$\mathrm{r}(\bullet)$ is a function similar to $\Psi_{\mathrm{i}}(\bullet)$.

Then the problem of stabile reengineering can be presented as follows:

$\sum_{\mathrm{j}=1}^{\mathrm{R}} \mathrm{C}_{\mathrm{jL}_{\mathrm{i}}} \mathrm{W}_{\mathrm{jL}_{\mathrm{i}}} \mathrm{r}\left(\mathrm{H}_{\mathrm{jL}_{\mathrm{i}}}\right) \rightarrow \min _{\mathrm{H}_{\mathrm{j}_{\mathrm{i}}}}$

$$
\Omega:\left\{\begin{array}{l}
\sum_{i=1}^{m} f_{i}^{\prime \prime} \geq \sum_{i=1}^{m} f_{i} \\
H_{j L_{i}} \in\left(\begin{array}{l}
\sum_{i=1}^{n}\left(r\left(\left\{M_{L_{i}}^{\prime \prime}\right\}\right)-r\left(\left\{M_{L_{i}}\right\}\right)\right) \\
+\sum_{i=1}^{n}\left(r\left(\left\{R_{L_{i}}^{\prime \prime}\right\}\right)-r\left(\left\{R_{L_{i}}^{\prime \prime}\right\}\right)\right) \\
+\sum_{i=1}^{n}\left(r\left(\left\{Z_{L_{i}}^{\prime \prime}\right\}\right)-r\left(\left\{Z_{L_{i}}\right\}\right)\right) \\
+\sum_{i=1}^{n}\left(r\left(\left\{A_{L_{i}}^{\prime \prime}\right\}\right)-r\left(\left\{A_{L_{i}}\right\}\right)\right)
\end{array}\right)
\end{array}\right.
$$

Here $\mathrm{C}_{\mathrm{jL}_{\mathrm{i}}}$ are specific expenses on reengineering.

The described models of IS support types' structures and of IS functional structure are metamodels used for determination of general rules of transformation of requirements and substitutions for reengineering of IS support types. In order to detail these models we proposes to describe 'primary elements' of IS support types with the help of local technical and technical-economical criteria of efficiency analyzed in the paper ${ }^{[18]}$. Then fulfillment of the first requirement of stabile reengineering of a particular type of IS support can be described using the following reengineering function:

$$
X\left[\left\{S_{L_{i}}^{\prime}\right\}-\left\{S_{L_{i}}\right\}\right]=\sum_{j=1}^{k} \lambda_{i j}\left(Q_{i j}^{\prime}-Q_{i j}\right) / Q_{i j}^{\prime}
$$

Here:

$\mathrm{Q}_{\mathrm{ij}}=$ Technical and technical-economical characteristics of the $j$-th element of the i-th type of IS support before reengineering

$Q_{i j}^{\prime} \quad=$ Technical and technical-economical characteristics of the.$j$-th element of the $i$-th type of IS support before reengineering

$\lambda_{\mathrm{ij}}=$ Weights of the mentioned criteria $\mathrm{Q}_{\mathrm{ij}}^{\prime}$

$\sum_{\mathrm{j}=1}^{\mathrm{k}} \lambda_{\mathrm{ij}}=1$

$\mathrm{k}=$ Power of set that forms as a result of performance of composition $\left\{\mathrm{M}_{\mathrm{L}_{\mathrm{i}}}^{\prime}\right\} \mathrm{T}\left\{\mathrm{R}_{\mathrm{L}_{\mathrm{i}}}^{\prime}\right\}$

Then for IS as a whole the function of reengineering will be the follows:
$X\left[\left\{S^{\prime}\right\}-\{S\}\right]=\sum_{i=1}^{z} \lambda_{i} X\left[\left\{S_{L_{i}}^{\prime}\right\}-\left\{S_{L_{i}}\right\}\right]$

Here $\lambda_{\mathrm{i}}$ are weights of IS support types, determining significance of a $\mathrm{K}$ particular support type in IS $\sum_{\mathrm{i}=1}^{\mathrm{z}} \lambda_{\mathrm{i}}=1$.

It's proposed to describe the compliance with the second requirement of stabile reengineering using the function of structural stability of IS support types $\mathrm{V}\left\{\mathrm{S}_{\mathrm{L}_{\mathrm{i}}}^{\prime \prime}\right\}$. For the proposed variant of support type reengineering it can be as following:

$$
\begin{aligned}
v\left\{S_{L_{i}}^{\prime \prime}\right\}= & r\left(\left\{M_{L_{i}}\right\} T\left\{R_{L_{i}}\right\}\right)-r\left(\left\{\Lambda_{L_{i}}^{\prime \prime}\right\} T\left\{M_{L_{i}}^{\prime \prime}\right\} T\left\{R_{L_{i}}^{\prime \prime}\right\}\right) \\
v\left\{S_{L_{i}}^{\prime \prime}\right\}= & r\left(\left\{M_{L_{i}}\right\} T\left\{R_{L_{i}}\right\}\right) \\
& -\left[r\left(\left\{\Lambda_{L_{i}}^{\prime \prime}\right\} T\left\{M_{L_{i}}^{\prime \prime}\right\} T\left\{R_{L_{i}}^{\prime \prime}\right\}\right)\right]^{n}, n=1,2, \ldots, N
\end{aligned}
$$

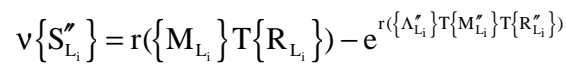

Here:

$\left\{\Lambda_{\mathrm{L}_{\mathrm{i}}}^{\prime \prime}\right\}=$ A set of weight coefficients determining the significance of modifications of components of IS support types structure during reengineering

$\mathrm{N}=$ Number of functional tasks of IS being modified

The description of structural stability reengineering function (26) is used for support types of InformationRetrieval IS (IRIS). The description of structural stability function (27) is used for support types of Information-Analytical IS (IAIS). The description of structural stability function (28) is used for support types of Information-Controlling IS. (ICIS)

In accordance to the proposed formalized descriptions we proposes to consider the task of stabile IS reengineering as the problem of determination such a state or the totality of states of IS support types' structures that in a general case can be described as following:

$\omega\left(S^{*}\right)=v\left\{S_{L_{\mathrm{i}}}^{\prime \prime}\right\} \cdot X\left[\left\{S^{\prime}\right\}-\{S\}\right]$

Here $\omega\left(\mathrm{S}^{*}\right)$ is a description of IS using metamodels similar to (1) after completion of reengineering.

\section{RESULTS}

The article contains a theoretical generalization of and a new solution of the following scientific problems: 
Development of a complex of IS mathematical models at different stages of reengineering; development of a mathematical model of stabile IS reengineering; development of formalized description of reengineering function and structural stability function. Using these models and descriptions, we developed the "primary elements" of technology stable reengineering IS. Its usage at different stages of IS designing allows to improve the efficiency of IS modernization and to reduce the amount of work on modification of individual supports types. The results of the analysis of main approaches to enterprise and IS reengineering as well as of existing methods and instrumental tools of enterprise and IS reengineering lead us to the conclusion that the main drawback of the existing methods and tools of IS reengineering is lack of a single complex of interrelated models and methods of analysis and synthesis of structures of IS support types optimal by the given efficiency criteria of structures of IS support types. This determines the main scientific purpose of the article and the tasks of the study.

\section{DISCUSSION}

Stabile reengineering mathematical models: The process of stabile reengineering at the various stages of it was formalized in mathematical model. The models are support varicose types of information systems. The function (26) can be used to complete the stabile process of reengineering Information-Retrieval IS (IRIS), the description in of structural stability function (27), exactly used to complete the process of reengineering Information-Analytical IS (IAIS) and the description of structural stability function (26) is used for support types of Information-Controlling IS (ICIS). The generally description of structural stability function which presents the problem of determination such a state or the totality of states of IS support types' structures can be described in description (29). All these mathematical descriptions can de used to evaluate the task of reengineering information systems at the various their types, and determine if the process of reengineering is feasible or not without starting the process of reengineering with real projects. This is the first time when process of reengineering and the process of stabile reengineering will be formalized in mathematical functions. Every reengineering project manager can use these models to define the success of the project early.

\section{CONCLUSION}

The developed models helps the system analyst to define if the reengineering process for the functional structure of information system will be stabile and effective or not, and if it more feasible than creating new information system.

\section{REFERENCES}

1. Suvojit Choton Basu, Prashant P. Palvia and Leida Chen, 2003. Business process management. encyclopedia of library and information science. DOI: 10.1081/E-ELIS-120008818

2. Joseph Fong and Shi-Ming Huang, 2001. Information Systems Reengineering. 1st Edn., Springer, ISBN: 10: 9813083158, pp: 250.

3. Hui-Liang Tsai, 2003. Information Technology and Business Process Reengineering: New Perspectives and Strategies. Praeger Publishers, ISBN: 10: 1567206328, pp: 320.

4. Qingyu Zhang and Mei Cao, 2002. Business process reengineering for flexibility and innovation in manufacturing.

http://www.emeraldinsight.com/10.1108/02635570 210421336

5. Dr, Z.Z., 2008. Business Process-Reengineering: 7 Critical Success Factors for a Smooth Transformation of Your Organization Processes. Wordclay, ISBN: 13: 978-1604813265, pp: 232.

6. Olivera Marjanovic, 2000. Supporting the "soft" side of business process reengineering. Bus. Process Manage. J., 6: 43-55. DOI: $10.1108 / 14637150010313339$

7. Joseph Fong, 2006. Information Systems Reengineering and Integration. 2nd Edn., Springer, IISBN: 10: 1846283825, pp: 368.

8. Ralph L. Kliem, 2000. Risk Management for Business Process Reengineering Projects. Inform. Syst. Manage., 17: 1-3. DOI: 10.1201/1078/43193.17.4.20000901/31256.12

9. Evlanov, M.V., Abu-Sarhan and A.M. Zahi, 2002. The reengineering process modeling conception of corporative information system. Manage. Inform. Syst. Devic., 119: 27-31.

10. Hammer, M. and J. Champy, 2003. Reengineering the Corporation: A Manifesto for Business Revolution (Collins Business Essentials). Rev Upd Edn., Collins Business, ISBN: 10: 0060559535, pp: 272.

11. Hammer, M. and J. Champy, 1996. Reengineering the Corporation: A Manifesto for Business Revolution. Harperbusiness.

12. Kevin G. Coleman, Jim Ettwein, Clelland Johnson, Dick Pigman and Deborah Pulak, 1996. Reengineering Mis: Aligning Information Technology and Business Operations. IGI Global. ISBN: 10: 1878289306, pp: 441. 
13. Davenport, T.H., 1993. Process Innovation: Reengineering Work through Information Technology. Harvard Business School Press, ISBN: 13: 978-0875843667, pp: 337

14. Hammer, M., 1990. Reengineering work: Don't automate Obliterate. Harvard business review. 104.

15. Hammer, M. and S. Steven, 1999. How process enterprises really work?

http://www.ida.liu.se/ TDEI36/documents/hammer _stanton.doc

16. David Paper and Ruey-Dang Chang, 2005. The state of business process reengineering: a search for success factors. Total Qual. Manage. Bus. Excellence, 16: 121-133. DOI: $10.1080 / 1478336042000309907$
17. Melissa Cook, 1996. Building Enterprise Information Architectures: Reengineering Information Systems. Prentice Hall PTR, ISBN: 10: 0134402561, pp: 224.

18. Avramenko, V.P., Sadat Kkhudir and Abu Sarhan Zahi, 2001. Measures the efficiency functioning the distributed corporative system and formulation problems their optimization. Manage. Inform. Syst. Devic., 117: 109-117. 